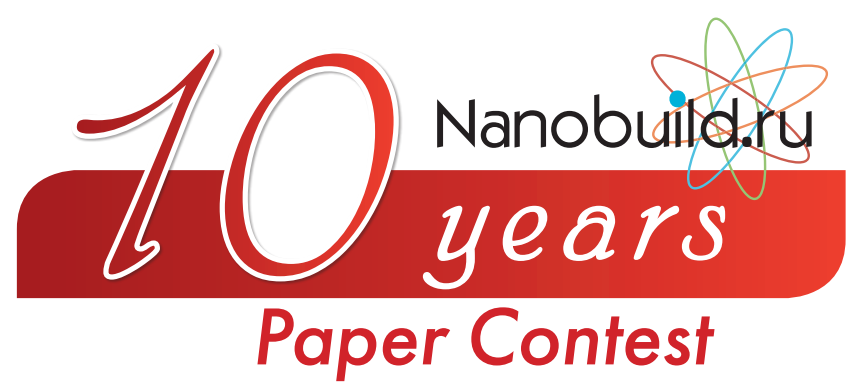

UDC 620.178

Author: DEMCHENKO Maria Vyacheslavovna, Assistant, Ufa State Petroleum Technological University (USPTU), Department «Technological Machines And Equipment»; 450062, Ufa, Kosmonavtov str. 1, Russia, e-mail: m.v.demchenko@yandex.ru;

Author: KUZEEV Iskander Rustemovich, Professor, Doctor of Engineering, Ufa State Petroleum Technological University (USPTU), Head of the Department «Technological Machines and Equipment»; 450062, Ufa, Kosmonavtov str. 1, Russia

\title{
REGULARITIES OF WELDED JOINT SURFACE RELIEF MORPHOLOGY CHANGE OF OIL AND GAS EQUIPMENT UNDER OPERATING CONDITIONS
}

\section{EXTENDEd Abstract:}

Methods that are used to study the fine structure of constructional materials are becoming more popular. Interdisciplinary approaches are important for explaining the relation between macrolevel processes and higher levels of metal destruction mechanisms research. Synergetics properly reflects the essence of natural processes, in particular the plastic deformation of metals. It is known when energy is supplied from outside, the open system organizes itself, striving to produce minimum of entropy. In this case when the accommodative mechanism is exhausted, the system passes to another dissipative structure with a dramatic change in properties. The authors studied deformation processes of outer layers and internal subsurface volumes of a metal when welded joints are deformed. It is shown that the zone of thermal influence in a welded joint is the area of discharge of the supplied energy and the zone of accommodation of the plastic deformation of the welded joint. The deformations of a new and embrittled metal after the 
operation run in different ways. This difference is taken as the basis for the assumption about the welded joint continuity preservation mechanisms under deformation. The microrelief of the welded joint on the surface and in the internal subsurface volumes zones has been investigated: welded seam, zone of influence, base metal. The relief parameters on micro-, nanolevel have been quantitatively evaluated: dispersion $R_{\mathrm{a}}$ and asymmetry $R_{\mathrm{sk}}$ according to GOST R ISO 4287-2014. It is shown that all parameters increase in the zone of thermal influence and are sensitive to discontinuities in the form of microcracks. One should note that the deformation relief is self-similar at various hierarchical levels. Fractal analysis of welded joint zones has been performed. It is shown that under deformation fractality increases in the zone of thermal influence.

Key words: welded joint, surface deformation relief, etching topography, synergetics, energy dissipation, laser scanning microscopy.

DOI: dx.doi.org/10.15828/2075-8545-2018-10-4-39-56

MACHine-REAdAble INFORMATION ON CC-LiCENSES (HTML-CODE) IN METADATA OF THE PAPER

$<$ a rel="license" href="http://creativecommons.org/licenses/by/4.0/" $><$ img alt="Creative Commons License" style="borderwidth:0" src="https://i.creativecommons.org/l/by/4.0/88x31.png" $/></ \mathrm{a}><$ br $/><$ span xmlns:dct="http://purl.org/ $\mathrm{dc} /$ terms/" href="http://purl.org/dc/dcmitype/Text" property="dct:title" rel="dct:type" $>$ Regularities of welded joint surface relief morphology change of oil and gas equipment under operating conditions $</$ span $>$ by $<$ a xmlns:cc="http:// creativecommons.org/ns\#" href="Nanotehnologii v stroitel'stve = Nanotechnologies in Construction. 2018, Vol. 10, no. 4, pp. 39-56. DOI: dx.doi.org/10.15828/2075-8545-2018-10-4-39-56. " property="cc:attributionName" rel="cc:attributionU RL">Demchenko M.V., Kuzeev I.R. $</$ a $>$ is licensed under a < a rel="license" href="http://creativecommons.org/licenses/ by/4.0/">Creative Commons Attribution 4.0 International License $</$ a $>$. $<$ br $/>$ Based on a work at $<$ a xmlns:dct="http:// purl.org/dc/terms/" href=" http://nanobuild.ru/en_EN/nanobuild-4-2018/" rel="dct:source"> http://nanobuild.ru/ en_EN/nanobuild-4-2018/</a $>$. $<$ br / Permissions beyond the scope of this license may be available at $<$ a xmlns:cc="http:// creativecommons.org/ns \#" href="m.v.demchenko@yandex.ru" el="cc:morePermissions">m.v.demchenko@yandex.ru</a $>$.

\section{References:}

1. Makarenko O.A., Kravtsov V.V., Ibragimov I.G. Resurs stal'nykh rezervuarov [Resource of steel tanks]. Saint-Petersburg, «Nedra», 2008. 200 p. (In Russian).

2. Zaynullin R.S., Morozov Ye.M. Bezopasnoye razvitiye treshchin v elementakh obolochechnykh konstruktsiy [Safe development of cracks in the elements of shell structures]. SaintPetersburg, «Nedra», 2005. 168 p. (In Russian).

3. Goritskiy V.M. Diagnostika metallov [Diagnostics of metals]. Moscow, Metallurgizdat, 2004. 408 p. (In Russian). 
4. Ivanova V.S., Balankin A.S., Bunin I.Zh., Oksogoyev A.A. Sinergetika I fraktaly v materialovedenii [Synergetics and fractals in materials science]. Moscow, Nauka, 1994. $383 \mathrm{p}$. (In Russian).

5. Ivanova V.S., Zakirnichnaya M.M., Kuzeyev I.R. Sinergetika i fraktaly. Universal'nost' mekhanicheskogo povedeniya materialov [Synergetics and fractals. Universality of mechanical behavior of materials]. Ufa, USPTU, 1998. Part 1. 144 p. (In Russian).

6. Shanyavskiy A.A. Modelirovaniye ustalostnykh razrusheniy metallov [Modeling fatigue fractures of metals]. Ufa, Monografiya, 2007. 500 p. (In Russian).

7. Demchenko A.A., Demchenko M.V., Sisanbaev A.V., Naumkin Ye.A.,Kuzeev I.R. Vzaimosvyaz' deformatcionnogo rel'yefa poverkhnosti i stepeni povrezhdennosti stali pri malotsiklovom nagruzhenii [Interrelation of the deformation relief of the surface and the degree of steel damage under low-cycle loading]. Khimicheskaya fizika i mezoskopiya. [Chemical physics and mesoscopy]. 2012. Vol. 14. no. 3. pp. 426-429. (In Russian).

8. Demchenko A.A., Demchenko M.V., Sisanbaev A.V., Kuzeev I.R. Issledovaniya fraktal'noy razmernosti deformatcionnoy poverkhnosti stali lazernym skaniruyushchim metodom [Investigations of the fractal dimension of the deformation surface by means of laser scanning method]. Khimicheskaya fizika I mezoskopiya. [Chemical physics and mesoscopy]. 2012. Vol. 14. no. 4. pp. 569-573. (In Russian).

9. Pleshanov V.S., Panin V.Ye., Kobzeva S.A., Lebedeva N.A., Kozlov A.V. Mezomasshtabnyy mekhanizm lokalizatsii deformatsii pri rastyazhenii polikristallov nizkouglerodistoy stali s lineynym i kontsentratorami napryazheniy [Mesoscale mechanism of localization of deformation during stretching of polycrystals of low-carbon steel with linear stress concentrators]. Fiz. mezomekh. [physicalmesomechanics] 2001. Vol. 4, no. 6. pp. 95-104. (In Russian).

10. Pleshanov V.S., PaninV.Ye., Kobzeva S.A. Kinetika polosovykh mezoskopicheskikh struktur i razrusheniye polikristallov austenitnoy khromonikelevoy stali s protyazhennym i makrokontsentratorami napryazheniy [Kinetics of band mesoscopic structures and destruction of polycrystals of austenitic chromium-nickel steel with extended stress macroconcentrators]. Fiz. mezomekh [Physical mesomechanics]. 2002. Vol. 5, no. 6. pp. 65-71. (In Russian).

11. Pleshanov V.S., PaninV.Ye., Kibitkin V.V., Lebedeva N.A. Evolyutsiya mezostruktury I kinetika nakopleniya ustalostnykh povrezhdeniy v svarnykh soyedineniyakh konstruktsionnoy stali v usloviyakh, blizkikh k ploskomu napryazhennomu sostoyaniyu [Evolution of mesostructure and the kinetics of accumulation of fatigue damages in welded joints of structural steel under conditions close to a plane stressed state]. Fiz. mezomekh. [Physical mesomechanics]. 2001. Vol. 4, no. 6, pp. 105-117. (In Russian).

12. Poletayev Yu.V. Mekhanizm lokal'nogo razrusheniya zony termicheskogo vliyaniya svarnykh soyedineniy primalotsiklovomnagruzhenii [The mechanism of local destruction of the zone of thermal influence of welded joints under low-cycle loading]. Inzhenernyy vestnik Dona [Engineering Journal of Don]. 2011.Vol. 18, no. 4. pp. 398-405. (In Russian).

13. PaninV.Ye. Volnovaya priroda plasticheskoy deformatsii tverdykh tel [Wave nature of plastic deformation of solids]. Izvestiya vuzov. Fizika [Proceedings of high schools. Physics]. 1990. Vol. 33, no. 2. pp. 3 - 18. (In Russian). 
14. Frolov K.V., PaninV.Ye., Makhutov N.A., Zuyev L.B., Danilov V.I., Mnikh N.I. Relaksatsionnyyevolnypriplasticheskoydeformatsii [Relaxation waves under plastic deformation]. Izvestiya vuzov. Fizika [Proceedings of high schools. Physics]. 1990.Vol. 33, no. 2, pp. 19-35. (In Russian).

15. Zuyev L.B., Danilov V.I., Barannikova S.A. Fizika makrolokalizatsii plasticheskogo techeniya [Physics of macrolocalization of plastic flow]. Novosibirsk, Nauka, 2008. 327 p. (In Russian).

16. GOST R ISO 4287-2014. Geometricheskiye kharakteristiki izdeliy. Struktura poverkhnosti. Profil'nyy metod. Terminy, opredeleniya i parametry struktury poverkhnosti [Geometrical characteristics of products. Surface structure. Profile method. Terms, definitions and parameters of the surface structure]. Moskva, Standartinform, 2015. 18 p. (In Russian).

17. Demchenko M.V., Sisanbaev A.V., Kuzeev I.R. Research of state of metal welded joint by deformation and corrosion surface projection parameters. Nanotehnologii v stroitel'stve $=$ Nanotechnologies in Construction. 2017, Vol. 9, no. 5, pp. 98-115. DOI: dx.doi. org/10.15828/2075-8545-2017-9-5-98-115. (In Russian).

18. Rybakova L.M, Kuksenova L.I. Struktura i iznosostoykost' metalla [Structure and wear resistance of metal]. Moskva, Mashinostroyeniye, 1982. 212 p. (In Russian).

19. Vladimirov V.I. Fizicheskaya priroda razrusheniya metallov [The physical nature of the destruction of metals]. Moskva: Metallurgiya, 1984. 280 p. (In Russian).

20. Panin V.Ye. Osnovy fizicheskoy mezomekhaniki [Fundamentals of physical mesomechanics]. Fizicheskaya Mezomekhanika [Physical mesomechanics].1998. Vol. 1, no. 1. pp. 5-22. (In Russian).

21. Panin V.Ye., Likhachev V.A., Grinyayev Yu.V. Strukturnyye urovni deformatsii tverdykh tel [Structural levels of deformation of solids]. Novosibirsk, Nauka, 1985. 254 p. (In Russian).

22. Nikolis G., Prigozhiy I. Samoorganizatsiya v neravnovesnykhsistemakh [Self-organization in nonequilibrium systems]. Moskva, Mir. 1979. 300 p. (In Russian).

\section{DEAR COLleAgues!}

THE REFERENCE TO THIS PAPER hAS THE FOLLOWING CITATION FORMAT:

Demchenko M.V., Kuzeev I.R. Regularities of welded joint surface relief morphology change of oil and gas equipment under operating conditions. Nanotehnologii v stroitel'stve $=$ Nanotechnologies in Construction. 2018, Vol. 10, no. 4, pp. 39-56. DOI: dx.doi.org/10.15828/2075-8545-2018-10-4-39-56. (In Russian). 


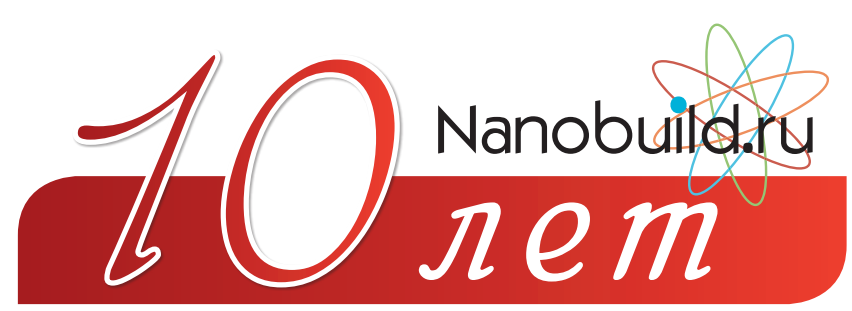

конкурс статей

уДК 620.178

Автор: ДЕМЧЕНКО Мария Вячеславовна, ассистент каф. «ТМО», ФГБОУ ВО «Уфимский государственный нефтяной технический университет»; ул. Космонавтов, 1, г. Уфа, Россия, 450062, e-mail: m.v.demchenko@yandex.ru;

Автор: КУЗЕЕВ Искандер Рустемович, проф., д-р техн. наук, зав. каф. «Технологические машины и оборудование», ФГБОУ ВО «Уфимский государственный нефтяной технический университет»; ул. Космонавтов, 1, г. Уфа, Россия, 450062

\section{ЗАКОНОМЕРНОСТИ ИЗМЕНЕНИЯ МОРФОЛОГИИ РЕЛЬЕФА ПОВЕРХНОСТИ СВАРНОГО СОЕДИНЕНИЯ НЕФТЕГАЗОВОГО ОБОРУДОВАНИЯ В УСЛОВИЯХ ЭКСПЛУАТАЦИИ}

\section{АННОТАЦИЯ К СТАТЬЕ (АВТОРСКОЕ РЕЗЮМЕ, РЕФЕРАТ):}

Все более востребованными становятся методы, направленные на исследование тонкой структуры конструкционных материалов. Для объяснения взаимосвязи процессов макроуровня и более высоких уровней исследования механизмов разрушения металлов важны междисциплинарные подходы. Адекватно отражает суть природных процессов, в частности процессов пластической деформации металлов, наука синергетика. Известно, что при подводе энергии извне открытая система самоорганизуется, стремясь к производству минимума энтропии. При этом, когда аккомодационный механизм исчерпывается, система переходит к другой диссипативной структуре с резким изменением свойств. В работе исследованы деформационные процессы внешних и приповерхностных слоев металла сварного соединения. Показано, что зона термического влияния в сварном соединении является областью сброса подводимой энергии и зоной аккомодации пластической деформации 
сварного соединения. Деформация исходного и охрупченного после эксплуатации металла осуществляется по-разному. Эта разница взята за основу предположения о механизмах сохранения сплошности сварного соединения при деформации. Исследован микрорельеф зон сварного соединения на поверхности и приповерхностных слоях: сварного шва, зоны влияния, основного металла. Проведена количественная оценка рельефа путем вычисления параметров на микро-, наноуровне: дисперсии $\mathbf{R}_{\mathrm{a}}$ и асимметрии $\mathbf{R}_{\mathrm{sk}}$ по $\Gamma$ ОСТ $\mathbf{P}$ ИСО 4287-2014. Показано, что все параметры повышаются в зоне термического влияния и являются чувствительными к несплошностям в виде микротрещин. Отмечено, что деформационный рельеф самоподобен на различных иерархических уровнях. Проведен фрактальный анализ зон сварного соединения. Показано, что при деформации фрактальность повышается в зоне термического влияния.

Ключевые слова: сварное соединение, деформационный рельеф поверхности, рельеф травления, синергетика, диссипация энергии, лазерная сканирующая микроскопия.

DOI: dx.doi.org/10.15828/2075-8545-2018-10-4-39-56

МАШИНОЧИТАЕМАЯ ИНФОРМАЦИЯ О СС-ЛИЦЕНЗИИ В МЕТАДАННЫХ СТАТЬИ (HTML-КОД):

$<$ a rel="license" href="http://creativecommons.org/licenses/by/4.0/" ><img alt="Creative Commons License" style="borderwidth:0" src="https://i.creativecommons.org/l/by/4.0/88x31.png" $/></ \mathrm{a}><$ br $/><$ span xmlns:dct="http://purl.org/dc/ terms/" href="http://purl.org/dc/dcmitype/Text" property="dct:title" rel="dct:type" $>$ Regularities of welded joint surface relief morphology change of oil and gas equipment under operating conditions $</$ span $>$ by $<$ a xmlns:cc="http://creativecommons. $\mathrm{org} / \mathrm{ns} \#$ " href="Nanotehnologii v stroitel'stve = Nanotechnologies in Construction. 2018, Vol. 10, no. 4, pp. 39-56. DOI: dx.doi.org/10.15828/2075-8545-2018-10-4-39-56. " property="cc:attributionName" rel="cc:attributionURL">Demchenko M.V., Kuzeev I.R. $</ a>$ is licensed under a $<$ a rel="license" href="http://creativecommons.org/licenses/by/4.0/" $>$ Creative Commons Attribution 4.0 International License $</ \mathrm{a}>$. $<\mathrm{br} />$ Based on a work at $<\mathrm{a}$ xmlns:dct="http://purl.org/dc/terms/" href=" http://nanobuild.ru/en_EN/nanobuild-4-2018/" rel="dct:source" $>$ http://nanobuild.ru/en_EN/nanobuild-4-2018/</ $\mathrm{a}>$. $<\mathrm{br} />$ Permissions beyond the scope of this license may be available at $<\mathrm{a}$ xmlns:cc="http://creativecommons.org $/ \mathrm{ns} \# "$ href="m.v.demchenko@yandex.ru" rel="cc:morePermissions">m.v.demchenko@yandex.ru</a> .

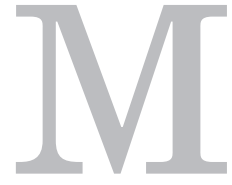

етоды расчета ресурса резервуаров постоянно совершенствуются. Достигнуто понимание о циклическом характере изменения рабочих параметров, связанных с заполнением и опорожнением резервуара. Показано влияние коррозионных процессов на возникновение поверхностных язв и микротрещин [1,2]. Совершенствование 
средств диагностики позволило выявить существенную неоднородность свойств сварных соединений [3]. Однако разрушения происходят, и это требует продолжения исследований и перевода этих исследований на более тонкие уровни организации конструкционных материалов.

Авторами работ $[4,5,6]$ и др. с позиций синергетики показано, что конструкции являются открытыми самоорганизующимися системами. При подводе энергии существует несколько механизмов адаптации материала к внешним воздействиям, которые могут реализоваться как последовательно, так и параллельно. В работе $[7,8]$ при исследовании изменения микрорельефа поверхности при деформировании стали на разных масштабных уровнях, авторы получили результаты, которые позволяют разработать метод оценки степени критичности состояния материала.

С учетом того, что большинство разрушений связано со сварными соединениями, актуальными являются исследования, направленные на изучение особенностей формирования и эволюции рельефа поверхности и приповерхностных слоев этих соединений. В работах [9-12] изучались механизмы разрушения сварных соединений. Показано, что процессы пластической деформации происходят на мезоуровне и локализуются в зоне термического влияния. В работах [13-15] показано, что аккомодационное скольжение зарождается только на границах раздела. Представляет интерес механизм деформации сварного соединения, а также разработка методов и средств, чувствительных к структуре внешних и приповерхностных слоев, подверженных деформации.

Методология исследования заключалась в статическом растяжении исходного и охрупченного после длительной эксплуатации металла сварного соединения. Отметим, что при изготовлении исходного металла сварного соединения была использована сварочная проволока с пределом прочности на разрыв $\sigma_{\text {в }}=558$ МПа и прокатные листы ВСт3сп с $\sigma_{\text {в }}=460$ МПа. Сварное соединение после эксплуатации получено путем вырезки из стыкового соединения листов резервуара, который эксплуатировался в нефтегазовой отрасли около 35 лет. Методом конфокальной лазерной сканирующей микроскопии исследован 3D-профиль сварного соединения и его основных зон: сварного шва, зоны термического влияния и основного металла. Поверхностные слои исследовались по изменению деформационного рельефа поверхности. Приповерхностные слои исследовались по изменению рельефа 
травления предварительно снятых механической полировкой поверхностных деформированных слоев.

Количественная оценка цифровых координат 3D профилей - дисперсии $\mathrm{R}_{\mathrm{a}}$, асимметрии $\mathrm{R}_{\mathrm{sk}}$ - проводилась по ГОСТ Р ИСО 4287-2014 [16]. При оценке результатов асимметрии рельефа полагали, что $\mathrm{R}_{\mathrm{sk}}<0$ отражает отрицательную морфологию и наличие микротрещин (см. рис. 1).

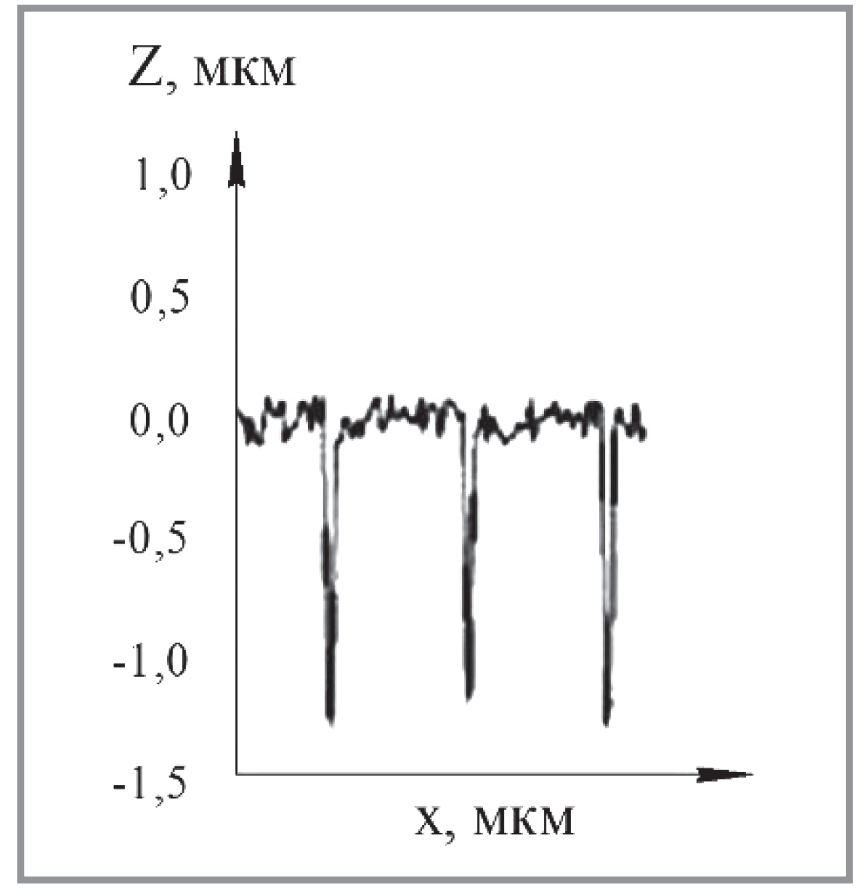

Рис. 1. Схема морфологии рельефа поверхности для отрицательного значения асимметрии

Фрактальность деформационного рельефа поверхности сварного соединения D вычислялась методом «объемного» box-counting в программном комплексе «ImageJ» при помощи плагина «MapFractalCount» по 2D-изображению рельефа в градациях серого.

В работе [17] нами предпринята попытка исследования сварного соединения до и после эксплуатации в нефтегазовой отрасли. Показано, что в сварном соединении после эксплуатации наблюдаются микротрещины, распространяющиеся между сварным швом и основным металлом по зоне термического влияния.

На рис. 2 схематично показана схема образования деформационного рельефа поверхности после растяжения сварного соединения. 


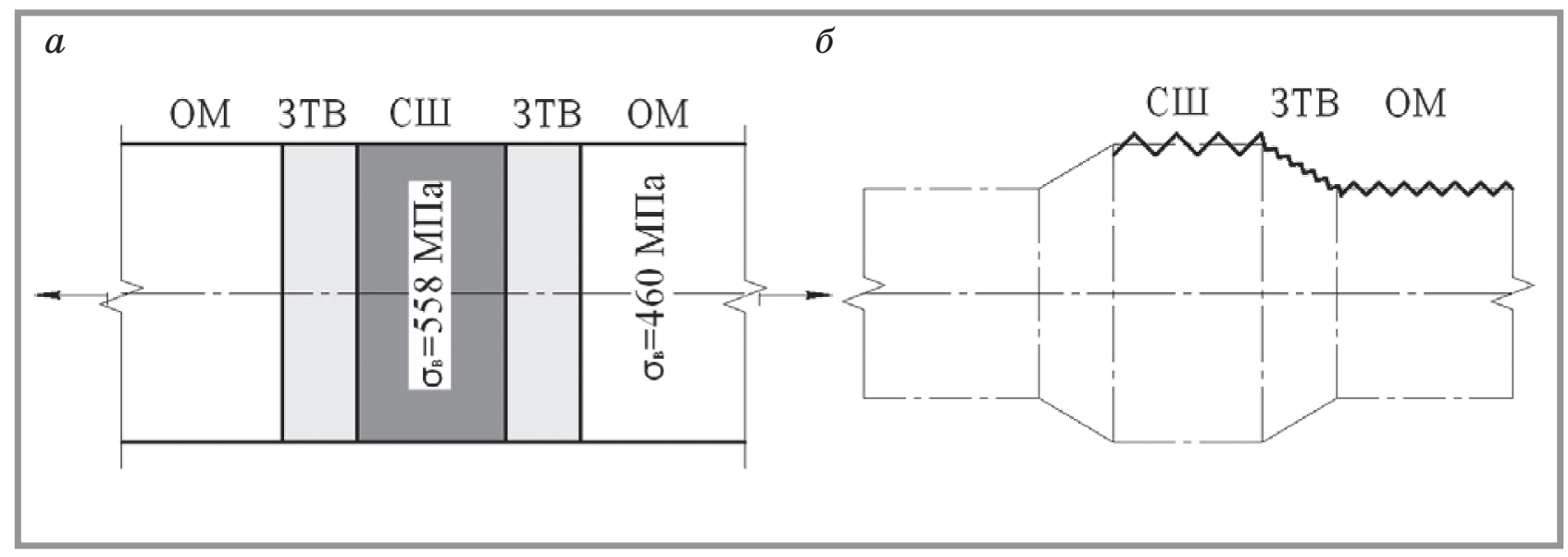

Puc. 2. Схема деформационного рельефа поверхности сварного соединения:

а) до растяжения, б) после растяжения

(СШ - сварной шов, ЗТВ - зона терлического влияния, ОМ - основной леталл)

Как видно на рис. 2, области сварного шва и основного металла деформируются параллельно оси растяжения образца, тогда как зона термического влияния «подстраивается» под соседние самостоятельно деформирующиеся области сварного соединения. Перепад высот деформационного рельефа, образованного при статическом растяжении, происходит из-за несовместности деформаций металлов с разными пределами текучести.

Исследователи [18-20] отмечают, что существует, как минимум, три стадии деформации материала. В работе [18] по рассеянию рентгеновских лучей выявлено, что с определенной стадии деформации материал по всему объему теряет сплошность, что подтверждается уменьшением плотности материала.

В работах $[13,14]$ показано, что аккомодационное скольжение зарождается только на границах раздела. В работах [9-11] отмечено, что деформация сварного соединения локализуется в зоне термического влияния на мезоуровне. В работе [12] отмечено, что эксплуатация сварного соединения в нефтехимической промышленности способствует разупрочнению границ зерен зоны термического влияния. Таким образом, можно предположить, что деформация сварного соединения начинается на границах раздела сварного соединения с разными механическими свойствами, а именно на границе сварного шва и зоны термического влияния, и локализуется в зоне термического влияния. 
Рассмотрим сварное соединение в качестве неравновесной открытой системы. В работах $[4-6,21,22]$ показано, что система выберет тот путь, который обеспечивает максимальную степень диссипации упругой энергии, и, в общем случае, наличие в пластически деформируемом кристалле поворотных мод и вихревого характера течения всегда предпочтительнее.

Перепад высот в рельефе - это последствие самоорганизии сварного соединения при пластической деформации с диссипацией энергии в ЗТВ в виде возникновения поворота объемов металла из-за стесненного сдвига. Относительное удлинение зоны термического влияния (по замеренным границам смещения зон) в горизонтальном направлении

Таблица 1

\section{Структура зон сварного соединения после деформации охрупченного металла}

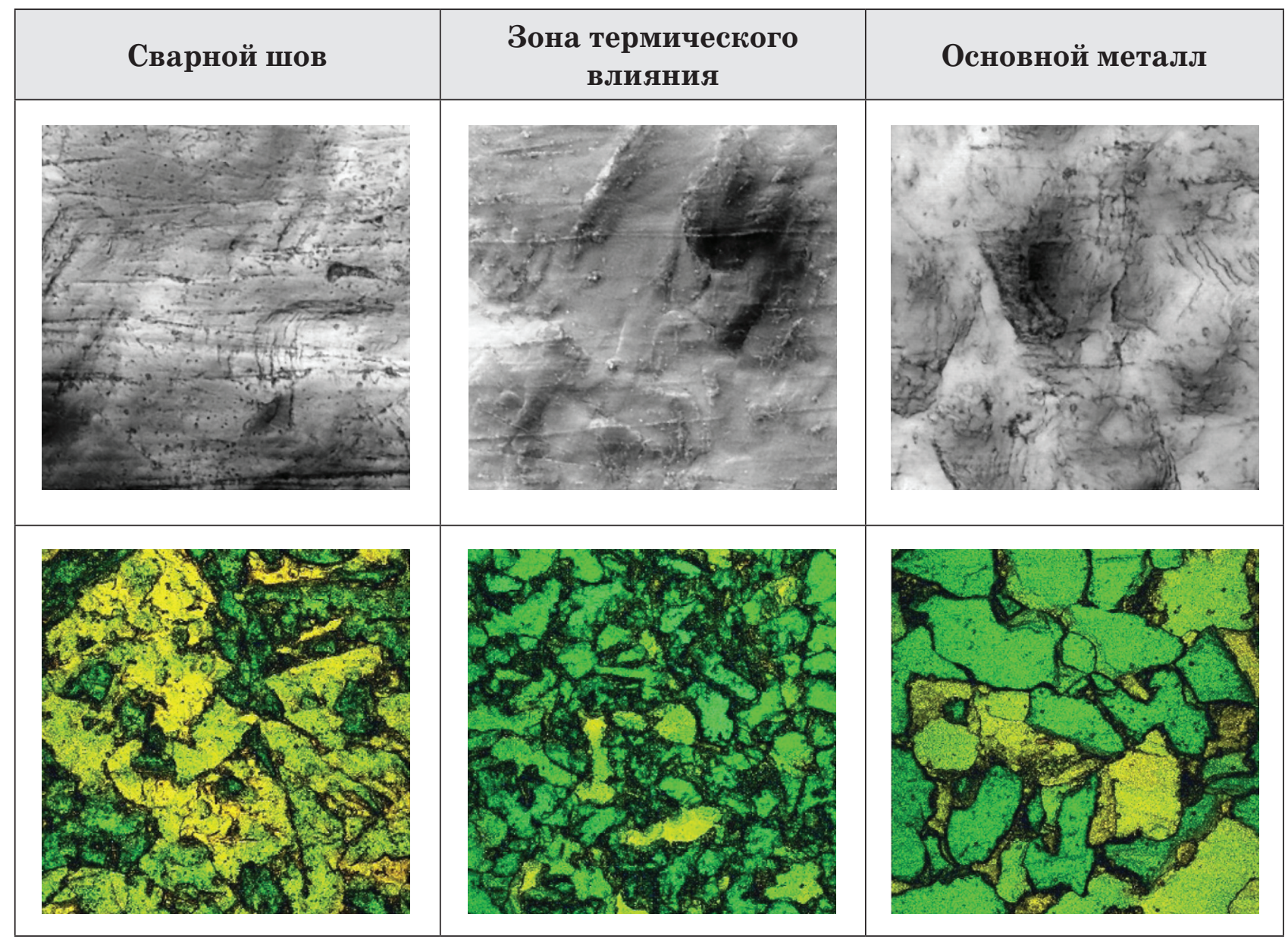


минимально по сравнению с относительным удлинением сварного шва и основного металла. Удлинение зоны термического влияния происходит в вертикальном направлении (см. рис. 2 б).

Для выявления потенциально опасной зоны сварного соединения нами проведен качественный и количественный анализ зон сварного соединения по отдельности.

В табл. 1 показаны внешние и приповерхностные слои зон сварного соединения. Масштаб (128х128) мкм.

Для деформационного рельефа поверхности характерно выявление полос деформации, отдельных линий скольжения в зернах и ступенек на поверхности. Для рельефа травления характерно выявление сетки границ зерен, различие между фазами, наличие микротрещин в структуре. Концентраторы напряжений в виде пор и микротрещин, нерелаксированные напряжения приводят к повышенной скорости протравливания структуры.

На рис. 3 приведены примеры 3D-структуры рельефа травления и деформационного рельефа поверхности охрупченного основного металла.

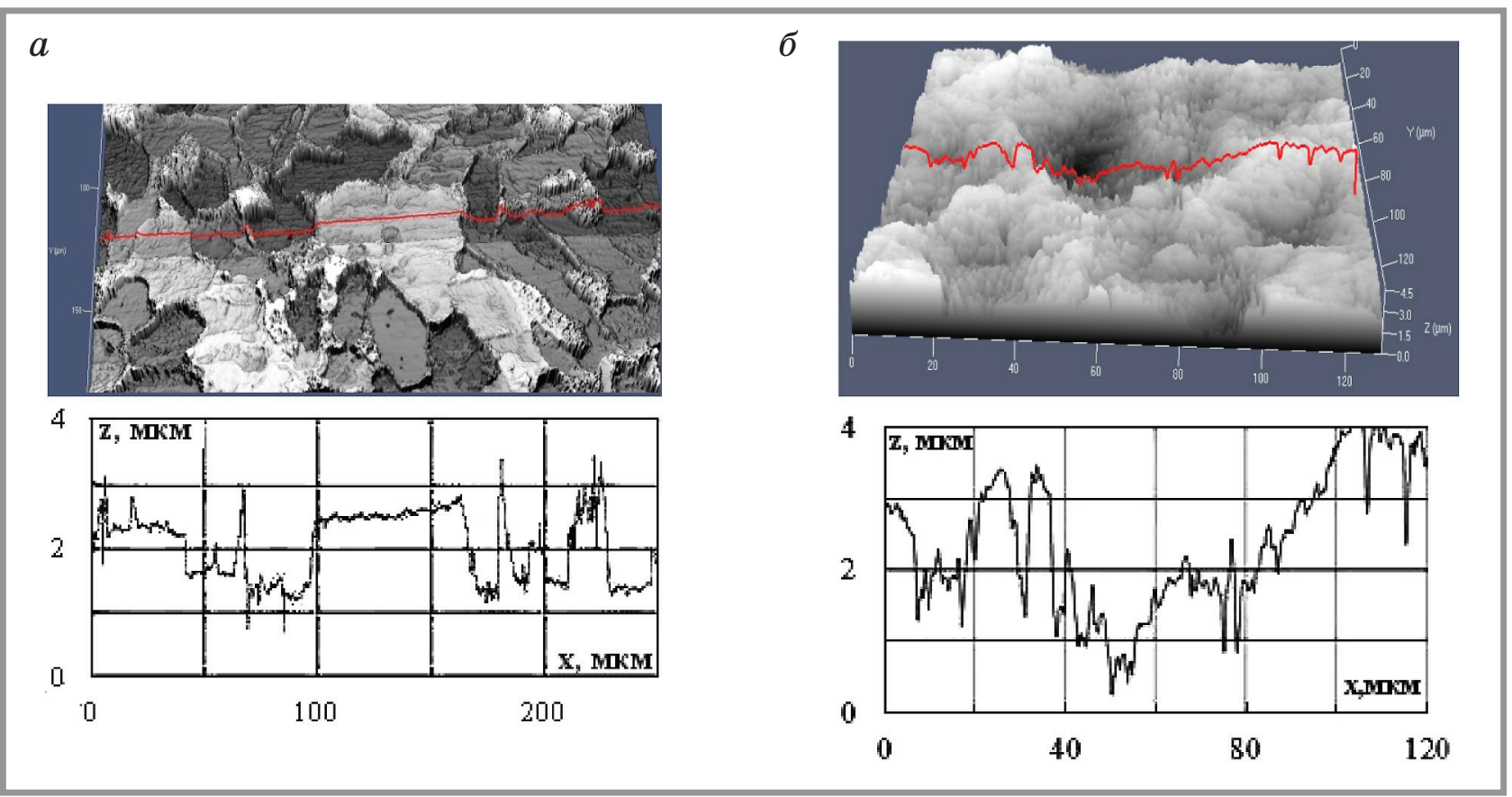

Рис. 3. Структура охрупченного металла:

а) рельеф травления; б) деформационный рельеф поверхности 
На рис. 3 видно, что рельеф травления зерен феррита и деформационный рельеф поверхности зерен имеет порядок 100-200 нм. Таким образом, возможно произвести оценку формирования рельфа поверхности и приповерхностных слоев в нанометровом диапазоне. Рассмотрим параметры морфологии рельефа поверхностных и приповерхностных слоев. В табл. 2 приведены параметры дисперсии $\mathrm{R}_{\mathrm{a}}$ и асимметрии $\mathrm{R}_{\mathrm{sk}}$ деформационного рельефа поверхностных слоев на разных масштабных уровнях, рассчитанные по 3D-профилям зон сварного соединения.

Таблица 2

Параметры морфологии деформационного рельефа поверхности зон сварного соединения на разных масштабных уровнях

\begin{tabular}{|c|c|c|c|c|c|c|c|}
\hline & \multirow{2}{*}{$\begin{array}{c}\text { Шерохо- } \\
\text { ватость R, } \\
\underset{\text { мкм }}{\text { м. }}\end{array}$} & \multicolumn{3}{|c|}{ Деформационный рельеф $\mathrm{R}_{\mathrm{a}}$, мкм } & \multicolumn{3}{|c|}{ Деформационный рельеф $\mathbf{R}_{\mathrm{sk}}$} \\
\hline & & & Исходный & Охрупченный & & Исходный & Охрупченный \\
\hline \multirow{3}{*}{ Макро } & \multirow{3}{*}{$4,2 \pm 0,6$} & СШ & $18,8 \pm 0,6$ & $14,9 \pm 0,6$ & СШ & $-0,1$ & $-0,2$ \\
\hline & & ЗТВ & $16,2 \pm 0,6$ & $15,1 \pm 0,6$ & ЗТВ & $-0,2$ & $-0,2$ \\
\hline & & $\mathrm{OM}$ & $13,6 \pm 0,6$ & $14,9 \pm 0,6$ & $\mathrm{OM}$ & 0,0 & $-0,1$ \\
\hline \multirow{3}{*}{ Мезо } & \multirow{3}{*}{$0,4 \pm 0,1$} & СШ & $2,1 \pm 0,1$ & $1,1 \pm 0,1$ & СШ & $-0,4$ & $-0,2$ \\
\hline & & ЗТВ & $1,2 \pm 0,1$ & $2,8 \pm 0,1$ & ЗТВ & 0,1 & $-1,3$ \\
\hline & & $\mathrm{OM}$ & $1,5 \pm 0,1$ & $1,2 \pm 0,1$ & $\mathrm{OM}$ & $-0,4$ & $-0,2$ \\
\hline \multirow{3}{*}{ Микро } & \multirow{3}{*}{$0,25 \pm 0,04$} & СШ & $1,00 \pm 0,04$ & $0,50 \pm 0,04$ & СШ & 0,1 & $-0,3$ \\
\hline & & ЗТВ & $0,40 \pm 0,04$ & $0,40 \pm 0,04$ & ЗТB & $-0,1$ & $-0,4$ \\
\hline & & $\mathrm{OM}$ & $0,60 \pm 0,04$ & $0,60 \pm 0,04$ & $\mathrm{OM}$ & 0,2 & $-0,5$ \\
\hline
\end{tabular}

Как видно из табл. 2, на всех масштабных уровнях значения параметра $\mathrm{R}_{\mathrm{a}}$ рельефа исходного металла коррелирует с размером зерна (наименьшее значение в ЗТВ, наибольшее в СШ), что не противоречит литературным данным. В охрупченном металле данная закономерность нарушается в ЗТВ на мезоуровне. На микроуровне в охрупченном металле корреляция с размером зерна присутствует, поскольку механизм релаксации микроконцентраторов напряжений уже завершен. На макроуровне в охрупченном металле также соблюдается корреляция с размером зерна, поскольку макроизменения структуры не локализованы в сварном соединении (шейка образовалась в основном металле). 
Асимметрия рельефа $\mathrm{R}_{\mathrm{sk}}=-1,3$ указывает на наличие микротрещин в зоне термического влияния охрупченного металла (см. рис. 1). На рис. 4 приведены картина 3D-профиля деформационного рельефа поверхности охрупченного металла зоны термического влияния на мезоуровне и профилограмма вдоль оси растяжения, на которой наблюдаются микротрещины с шагом 20 мкм, распространяющиеся по направлению максимальных касательных напряжений.

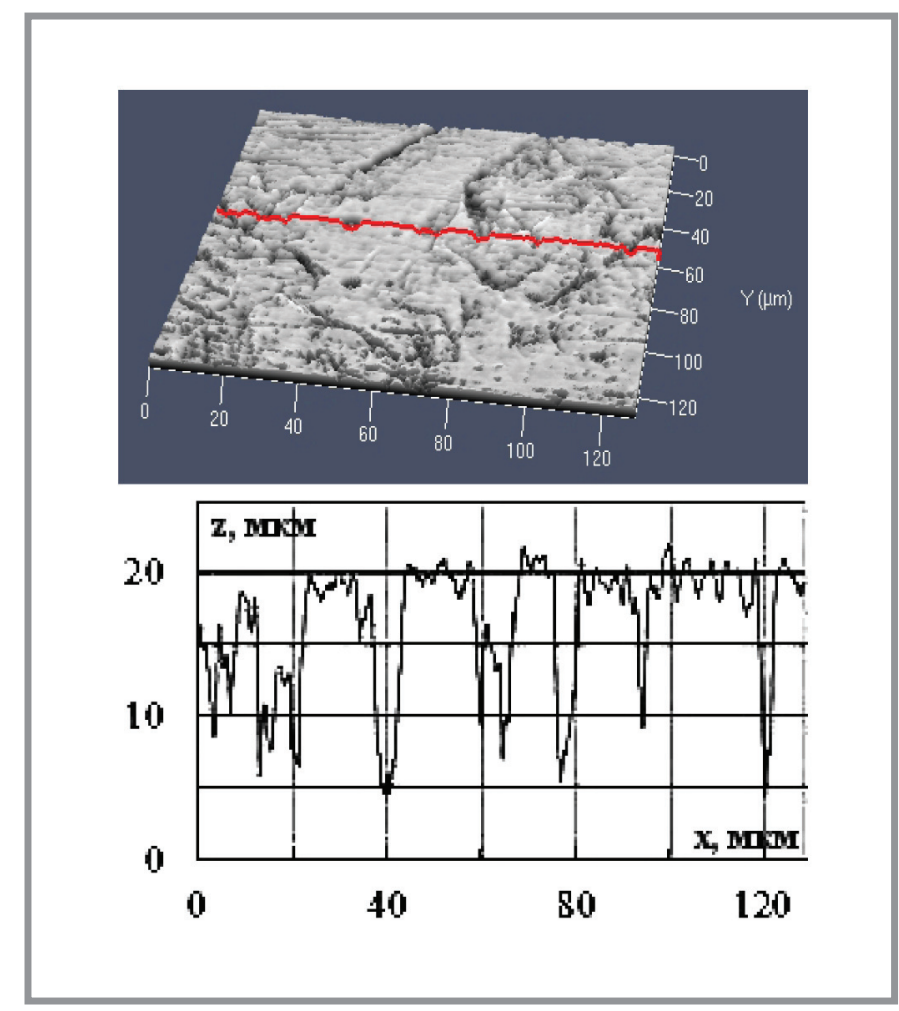

Рuc. 4. 3D-профиль деформационного рельефа поверхностных слоев охрупченного металла зоны термического влияния

При исследованиях сварного соединения обнаружено подобие деформационного рельефа поверхности на разных масштабных уровнях (см. рис. 5).

Проведена количественная оценка фрактальности координат деформационного рельефа каждой зоны сварного соединения на мезомасштабном уровне (в котором обнаружены полосовые структуры). B табл. 3 приведены значения фрактальности D, вычисленной по координатам 3D-рельефа. 


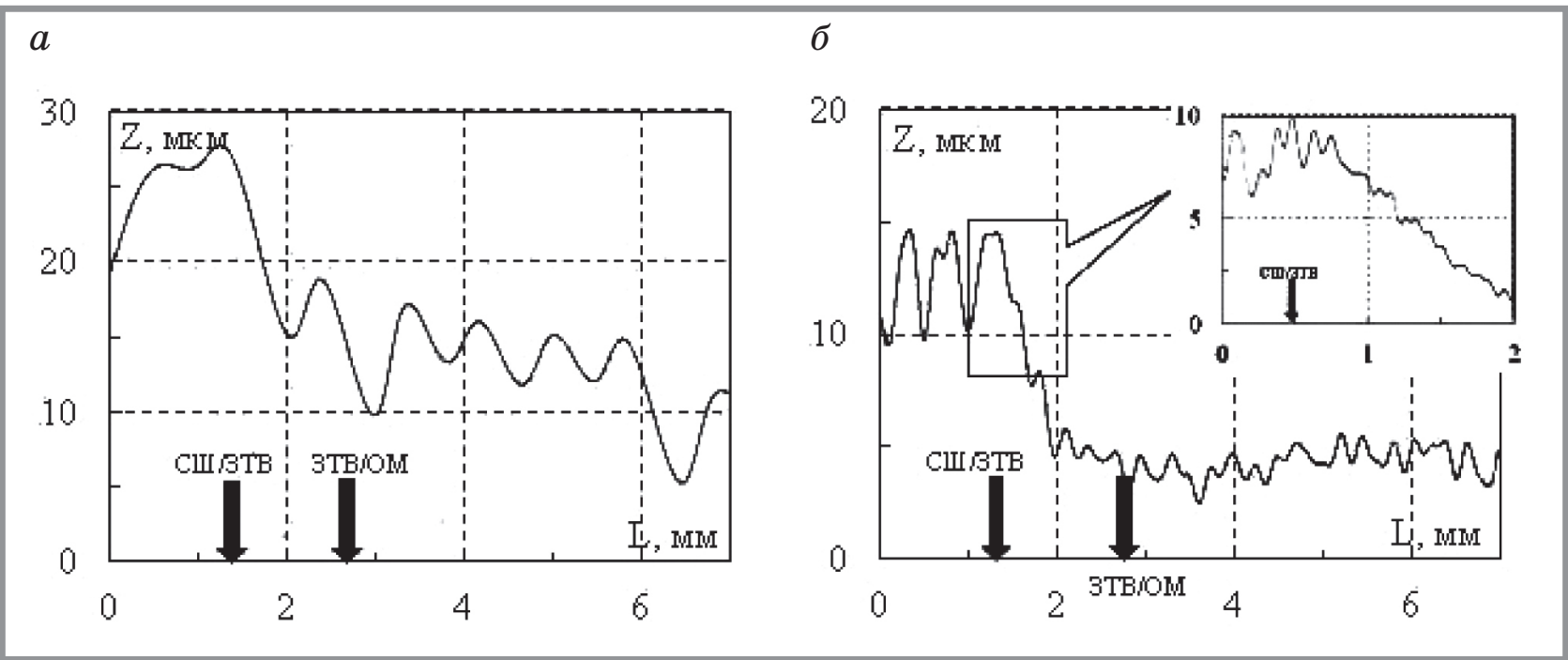

Рис. 5. Профиль деформационного рельефа поверхности сварного соединения на: а) макро-, б) мезо- и (на выделенном участке) микроуровне

Таблица 3

Фрактальность D-деформационного рельефа поверхности сварного соединения

\begin{tabular}{|c|c|c|c|}
\hline & Шероховатость & Исходный металл & Охрупченный металл \\
\cline { 1 - 3 } СШ & \multirow{2}{*}{2,2716} & 2,4833 & 2,4182 \\
\cline { 1 - 3 } 3ТВ & & 2,4038 & 2,5234 \\
\cline { 1 - 3 } OM & & 2,4254 & 2,4321 \\
\hline
\end{tabular}

Значение фрактальной размерности исходного металла коррелирует с размером зерна. Эта закономерность нарушена в ЗТВ охрупченного металла. Количественный параметр фрактальность, также как среднеарифметическое отклонение и асимметрия морфологии рельфа, чувствителен к несплошностям материала.

Параметры рельефа травления сварного соединения исследованы на мезомасштабном уровне, поскольку на данном уровне деформации зафиксированы изменения в структуре. В табл. 4 приведены параметры дисперсии $\mathrm{R}_{\mathrm{a}}$ и асимметрии $\mathrm{R}_{\mathrm{sk}}$ рельефа травления приповерхностных слоев, рассчитанные по 3D-профилям зон сварного соединения. 
Таблица 4

Параметры морфологии рельефа травления приповерхностных слоев зон сварного соединения

\begin{tabular}{|c|c|c|c|c|c|}
\hline \multicolumn{2}{|c|}{ Параметр рельефа травления $\mathbf{R}_{\mathrm{a}}$,мкм } & \multicolumn{3}{|c|}{ Параметр рельефа травления $\mathbf{R}_{\mathrm{sk}}$} \\
\hline & $\begin{array}{c}\text { Исходный ме- } \\
\text { талл }\end{array}$ & $\begin{array}{c}\text { Охрупченный } \\
\text { металл }\end{array}$ & $\begin{array}{c}\text { Исходный ме- } \\
\text { талл }\end{array}$ & $\begin{array}{c}\text { Охрупченный } \\
\text { металл }\end{array}$ \\
\hline СШ & $0,8 \pm 0,1$ & $0,8 \pm 0,1$ & СШ & 0,2 & 0,0 \\
\hline ЗТВ & $0,6 \pm 0,1$ & $0,9 \pm 0,1$ & $3 \mathrm{~TB}$ & 0,3 & $-1,0$ \\
\hline OM & $0,6 \pm 0,1$ & $0,7 \pm 0,1$ & OM & 0,2 & 0,5 \\
\hline
\end{tabular}

По табл. 4 видно, что значения параметров рельефа травления коррелируют с размером зерна. Нарушение этой закономерности проявляется в ЗТВ охрупченного металла, где параметр $\mathrm{R}_{\text {a }}$ выше, чем в СШ и OM. Асимметрия рельефа $R_{\mathrm{sk}}=-1,0$ указывает на наличие микротрещин в приповерхностных слоях ЗТВ охрупченного металла. На рис. 6 приведена профилограмма рельефа травления вдоль оси растяжения в приповерхностных слоях охрупченного металла, на которой наблюдаются острые впадины, характеризующие отрицательную асимметрию.

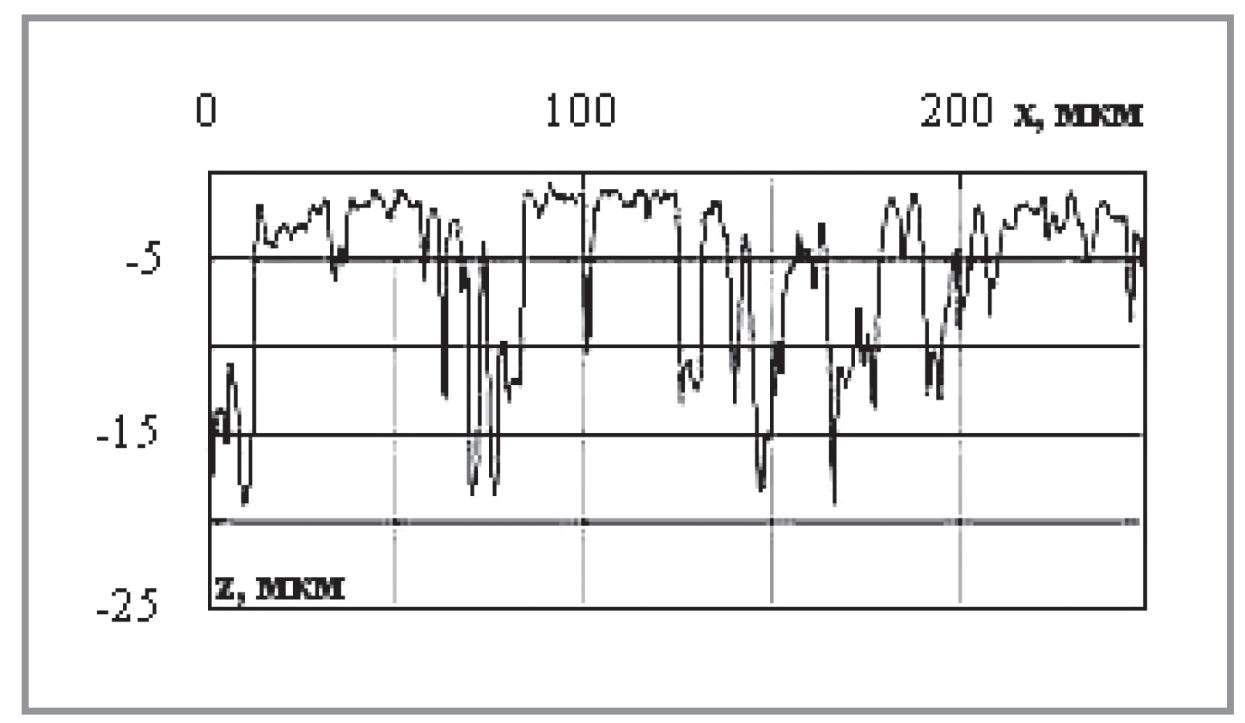

Рис. 6. Профиль рельефа травления в приповерхностных слоях охрупченного металла 
Таким образом, выявлена закономерность изменения морфологии деформационного рельефа и рельефа химического травления в условиях эксплуатации. Параметры дисперсия и фрактальность рельефа коррелируют с размером зерна металла и имеют тенденцию к росту по мере увеличения степени относительной деформации. В охрупченном металле данная корреляция нарушается. Дисперсия и фрактальность повышаются в зоне термического влияния на мезоуровне. Параметр асимметрия отражает качественные изменения в морфологии рельефа, такие, как появление острых впадин (микротрещин).

На основании проведенных исследований можно предложить использовать параметры дисперсии, асимметрии и фрактальности рельефа травления и деформационного рельефа поверхности зон сварного соединения в качестве параметров для исследования 3D-структуры сварного соединения в процессе эксплуатации.

\section{Библиографический список:}

1. Макаренко О.А., Кравиов В.В., Ибрагимов И.Г. Ресурс стальных резервуаров. СПб.: ООО «Недра», 2008. - 200 с.

2. Зайнуллин P.C., Морозов E.M. Безопасное развитие трещин в элементах оболочечных конструкций. - СПб.: Недра, 2005. - 168 с.

3. Гориикий В.М. Диагностика металлов. - Москва: Металлургиздат, 2004. - 408 с.

4. Иванова В.С., Баланкин А.С., Бунин И.Ж., Оксогоев А.А. Синергетика и фракталы в материаловедении. - Москва: Наука, 1994. - 383 с.

5. Иванова В.С., Закирничная М.М., Кузеев И.Р. Синергетика и фракталы. Универсальность механического поведения материалов. - Уфа :Изд-во УГНТУ, 1998. Ч. $1 .-144 \mathrm{c}$.

6. Шанявский A.A. Моделирование усталостных разрушений металлов. - Уфа: ООО «Монография», 2007. - $500 \mathrm{c}$.

7. Демченко А.А., Демченко М.В., Сисанбаев А.В., Наумкин Е.А., Кузеев И.Р. Взаимосвязь деформационного рельефа поверхности и степени поврежденности стали при малоцикловом нагружении // Химическая физика и мезоскопия. - 2012. T. 14 , № 3. - С. 426-429. 
8. Делченко А.А., Демченко М.В., Сисанбаев А.В., Кузеев И.Р. Исследования фрактальной размерности деформационной поверхности стали лазерным сканирующим методом // Химическая физика и мезоскопия. - 2012. - Т. 14, № 4. С. 569-573.

9. Плешанов В.С., Панин В.Е., Кобзева С.А., Лебедева Н.А., Козлов А.В. Мезомасштабный механизм локализации деформации при растяжении поликристаллов низкоуглеродистой стали с линейными концентраторами напряжений // Физ. мезомех. - 2001. - Т. 4, № 6. - С. 95-104.

10. Плешанов В.С., Панин В.Е., Кобзева С.А. Кинетика полосовых мезоскопических структур и разрушение поликристаллов аустенитной хромоникелевой стали с протяженными макроконцентраторами напряжений // Физ. мезомех. - 2002. - Т. 5 , № 6. - С. 65-71.

11. Плешанов В.С., Панин В.Е., Кибиткин В.В., Лебедева Н.А. Эволюция мезоструктуры и кинетика накопления усталостных повреждений в сварных соединениях конструкционной стали в условиях, близких к плоскому напряженному состоянию // Физ. мезомех. - 2001. - Т. 4, № 6. - С. 105-117.

12. Полетаев Ю.В. Механизм локального разрушения зоны термического влияния сварных соединений при малоцикловом нагружении // Инженерный вестник Дона. - 2011. - Т. 18, № 4. - С. 398-405.

13. Панин B.E. Волновая природа пластической деформации твердых тел // Известия вузов. Физика. - 1990. - Т. 33, № 2. - С. 3-18.

14. Фролов К.В., Панин В.Е., Махутов Н.А., Зуев Л.Б., Данилов В.И., Мних Н.И. Релаксационные волны при пластической деформации // Изв.вузов. Физика. 1990. - Т. 33, № 2. - С. 19-35.

15. Зуев Л.Б., Данилов В.И., Баранникова С.А. Физика макролокализации пластического течения. - Новосибирск: Наука, 2008. - 327 с.

16. ГОСТ Р ИСО 4287-2014. Геометрические характеристики изделий. Структура поверхности. Профильный метод. Термины, определения и параметры структуры поверхности. - М.: Стандартинформ, 2015. - 18 с.

17. Делченко М.В., Сисанбаев А.В., Кузеев И.Р. Исследования состояния сварного соединения металла по параметрам деформационного и коррозионного рельефа поверхности / / Нанотехнологии в строительстве. - 2017. - Том 9, № 5. - С. 98-115. DOI: dx.doi.org/10.15828/2075-8545-2017-9-5-98-115.

18. Рыбакова Л.М., Куксенова Л.И. Структура и износостойкость металла. - Москва: Машиностроение, 1982. - 212 с.

19. Владилиров В.И. Физическая природа разрушения металлов. - М.: Металлургия, 1984. $-280 \mathrm{c}$.

20. Панин В.E. Основы физической мезомеханики // Физ. мезомех. - 1998. - Т. 1, № 1. - C. 5-22. 
21. Панин В.Е., Лихачев В.А., Гриняев Ю.В. Структурные уровни деформации твердых тел. - Новосибирск: Наука, 1985. - 254 с.

22. Николис Г., Пригожий И. Самоорганизация в неравновесных системах. - М.: Мир, 1979. $-300 \mathrm{c}$.

УВАЖАЕМЫЕ КОЛЛЕГИ!

ПРИ ИСПОЛЬЗОВАНИИ МАТЕРИАЛА ДАННОЙ СТАТЬИ

ПРОСИМ ДЕЛАТЬ БИБЛИОГРАФИЧЕСКУЮ ССЫЛКУ НА НЕЁ:

Делченко М.В., Кузеев И.Р. Закономерности изменения морфологии рельефа поверхности сварного соединения нефтегазового оборудования в условиях эксплуатации // Нанотехнологии в строительстве. - 2018. - Том 10, № 4. - С. 39-56. DOI: dx.doi.org/10.15828/2075-8545-2018-10-4-39-56.

\section{DeAR COlleagues!}

THE REFERENCE TO THIS PAPER HAS THE FOLLOWING CITATION FORMAT:

Demchenko M.V., Kuzeev I.R. Regularities of welded joint surface relief morphology change of oil and gas equipment under operating conditions. Nanotehnologii v stroitel'stve $=$ Nanotechnologies in Construction. 2018, Vol. 10, no. 4, pp. 39-56. DOI: dx.doi.org/10.15828/2075-8545-2018-10-4-39-56. (In Russian). 